\title{
Nutrition and Female Fertility: An Interdependent Correlation
}

\author{
Erica Silvestris, Domenica Lovero and Raffaele Palmirotta* \\ Department of Biomedical Sciences and Human Oncology, University of Bari Aldo Moro, Bari, Italy
}

Besides aging, a number of non-modifiable lifestyle-related factors, such as smoking, elevated consumption of caffeine and alcohol, stress, agonist sports, chronic exposure to environmental pollutants, and other nutritional habits exert a negative impact on a women's fertility. In particular, metabolic disorders including diabetes, obesity, and hyperlipidemia commonly associated to hypercaloric diets are suspected to affect a woman's fertility either by direct damage to oocyte health and differentiation, or by indirect interference with the pituitary-hypothalamic axis, resulting in dysfunctional oogenesis. Obese women show decreased insulin sensitivity determining persistent hyperinsulinemia, which may be involved in the pathogenesis of Polycystic Ovary Syndrome. Thus, the reduced insulin secretion induced by dietary adjustments is an attractive non-pharmacological treatment to prevent infertility, and a Mediterranean diet

OPEN ACCESS

Edited by:

John Lui Yovich,

Pivet Medical Center, Australia

Reviewed by:

Syeda Nureena Zaidi,

Pivet Medical Center, Australia David Sharkey,

University of Adelaide, Australia

*Correspondence: Raffaele Palmirotta raffaelepalmirotta@gmail.com

Specialty section:

This article was submitted to Reproduction,

a section of the journal

Frontiers in Endocrinology

Received: 30 January 2019

Accepted: 13 May 2019

Published: 07 June 2019

Citation:

Silvestris $E$, Lovero $D$ and Palmirotta $R$ (2019) Nutrition and Female Fertility: An Interdependent Correlation.

Front. Endocrinol. 10:346. doi: 10.3389/fendo.2019.00346 aimed at maintaining normal body mass may be effective in the preservation of ovarian health and physiology. Furthermore, in relation to the oxidative stress as a co-factor of defective oocyte maturation, an appropriate intake of proteins, antioxidants and methyl-donor supplements (1-Carbon Cycle) may decrease the bioavailability of toxic oxidants resulting in the protection of oocyte maturation.

Keywords: obesity, infertility, anovulation, oocytes, diet, nutrition

\section{INTRODUCTION}

Infertility is a major problem in modern society and recurs in as much as $20-30 \%$ of the fertile female population. The American Society of Reproductive Medicine (ASRM) delineates infertility as the failure to conceive after one or more years of attempts of natural fertilization (1), with the World Health Organization (WHO) reporting up to 80 million women world-wide having been affected by this disease to date, with a prevalence of $~ 50 \%$ of all women in developing countries (2).

Besides a number of gynecological and systemic diseases affecting a woman's fertility, lifestyle factors and environmental conditions such as stressful jobs, unbalanced nutrition and unhealthy diet concur to interfere with reproduction safety in both women and men. Therefore, abnormal body weight and energy supply in terms of restrictions or excesses, as well as dietary enrichment in carbohydrates, fatty acids, proteins, vitamins and minerals all exert a detrimental impact on both ovulatory function and normal spermatogenesis. In addition to the negative interference with the safety of gametes, several nutrients of major diets also affect the implantation of a normal embryo.

In this paper, we revise how several lifestyles and rough nutritional regimens may interact with the reproductive health in women and how adequate nutritional support may improve fertility, according to studies from different clinical investigators and from our own observation. 


\section{MAJOR LIFESTYLE FACTORS AFFECTING WOMEN'S FERTILITY}

Beyond age, a number of lifestyle-related factors, such as excess body weight, obesity, smoking, intense sporting activity, alcohol consumption, drug addiction or abuse of other substances, have an adverse influence on female fertility. To date, most infertilities are usually treatable with major procedures belonging to the Assisted Reproductive Technology (ART) methods. However, the normalization of those factors could probably restore normal oocyte maturation and prevent the adoption of these procedures (3). Therefore, the major factors influencing infertility are listed and commented on in detail below.

\section{Age}

Besides lifestyle factors, woman's age is a major factor influencing the spontaneous probability of conception that already starts to decrease by $25-30$ years of age. Given the age-correlated deterioration of the ovarian reserve and oocyte quality, it is expected that the global trend of postponing maternity will result in increasing involuntary childlessness.

The improvement of oocyte vitrification resulting in pregnancy and live birth rate increases comparable to using fresh oocytes, which has offered a chance to cryopreserve oocytes for upcoming practice, presenting women with the possibility to delay their motherhood (4).

\section{Tobacco Smoking, Coffee and Alcohol Abuse}

Tobacco smoking markedly affects the reproductive health of both men and women, albeit acting in different ways. Heavy alcohol consumption indirectly affects the fertility when associated with nutritional or secondary health disorders (5). In females, smoking is associated with a rapid decline of ovarian reserves, delayed conception and heightened risk of spontaneous miscarriage, as well as a lower success rate from ART, while in males the percentage of normal semen morphology and motility is significantly reduced $(6,7)$. The influence of alcohol intake on reproductive outcomes has already been investigated in several studies, yet it is still impossible to demonstrate a significant correlation between alcohol intake and oocyte maturation and fertilization in females, and between male alcohol consumption and the rate of lost pregnancies $(8,9)$.

Firns and co-workers evaluated the impact of these lifestyle factors on in vitro fertilization (IVF) outcomes in 351 couples attending the PIVET Medical Center in Western Australia (5). Considering the quantity of collected oocytes, fertilization rates, pregnancy, and pregnancy loss, the multiple regression analysis showed that smoking strongly damages the quality of gametes in both sexes resulting in a reduction of ovarian reserve in women, and in a significant decrees in density, count, mobility and morphology of sperm in men. On the contrary, female alcohol consumption did not show any correlation with fertility parameters, while in males it even showed a positive effect on fertilization rate, in the cohort with an associated consumption of fruit and vegetables (5). Therefore, based on the results of the Authors and the current literature, there is an important impact of tobacco smoking on IVF clinical outcomes, whereas a defined role of alcohol assumption needs to be still defined (10).

Finally, evidence suggests that high intake of caffeine has a potential dose-response association resulting in both a longer time for conception and increased risk of pregnancy loss (10).

\section{Stress}

A stressful life, particularly in hard-working women, may contribute to cause infertility since symptoms related to anxiety and depression are described as more frequent in infertile than in fertile females. These features concur to produce a condition of psychological stress that may alter the physiological oocyte maturation (11). In a meta-analysis performed on 2,202 patients Purewal and contributors demonstrated that a favorable success of ART treatments leading to a higher rate of conception is obtainable in the absence of depression and anxious mental states (12).

Furthermore, it has been described that stress management by periodic relaxing training is helpful in decreasing the psychological distress in infertile women and may result in increased conception rates (13). In a very recent study performed on 72 women subjected to ART, Miller and coworkers demonstrated an increase in salivary cortisol levels during the pretreatment phase, followed by a reduction at the time of the embryo transfer. They, thus, concluded that the effects of both physiological and psychological stress on IVF outcome could not be always negative (14).

\section{Nutrition Styles and Body Weight}

Reproductive performance is definitely influenced by foods and type of nutrition. An unbalanced caloric and protein intake due to incorrect food consumption, responsible for severe under- or over-weight, leads to alterations of the ovarian function with subsequent increase in the infertility. Several studies exploring the effect on fertility of various dietary habits are based on data from extended studies including 116,678 females in the Nurses' Health Study II, that defined the reduced risk of fertility due to ovulatory disorder in women whose food regimen included low glycemic content and limited intake of nutrients (15). Variations of the body weight in terms of overweight, obesity or severe underweight associated to alterations of the energy balance are also suspected to produce ovulatory disorders. To this regard, it has been reported that the time to conceive is longer in women with body mass index (BMI) superior to $25 \mathrm{~kg} / \mathrm{m}^{2}$ or inferior to $19 \mathrm{~kg} / \mathrm{m}^{2}$, and that both overweight and obesity are significantly related with reduced pregnancy rate, increased supplies of gonadotrophins and higher miscarriage rate. High BMI is also associated with adverse pregnancy outcomes such as gestational diabetes, hypertension and premature births and unbalanced diets with a prevalence of carbohydrates, fatty-acids, proteins or vitamins and micronutrients definitely exert a negative impact on ovulation. Moreover, nutritional factors may influence not only oocyte maturation, but also quality of embryos and efficiency of implantation. However, more information regarding the role of nutrition in procreation is needed to provide guidelines devoted to nutritional management of infertile women (15). 


\section{Environmental Pollutants}

The Occupational Safety and Health Administration (OSHA) postulated that long-lasting exposure to chemical agents as organic solvents, heavy metals, aromatic amines, pesticides and vegetal toxins is related to reduced fertility and improved predisposition to occasional or recurrent miscarriages. Furthermore, environmental pollutants, determining the formation of DNA adducts and abasic sites construction, can induce DNA modifications in gametes and embryos by introducing genetic mutations once unrepaired (16).

\section{NUTRITIONAL DISORDERS}

A normal reproductive performance definitely requires a healthy nutrition since malnourished males and females are reported as major infertile populations in developing countries while, eating in excess, fast food consumption, hypercaloric dietary regimens and obesity, concur to infertility in well-developed and western societies.

Particularly in women, abnormal nutrition may permanently affect oocyte maturation, and a better understanding of the molecular events deranged in malnourished people would provide solutions for restoring normal reproductive functions.

\section{Malnutrition}

Deficient food intake, inadequate alimentary regimes, strong dietary restrictions and a general lack of nutrients result in loss of both body weight and physical performance, delayed puberty, lengthening of the post-partum interval to conception, lower gonadotropin secretion levels with alterations of the physiological ovarian cyclicity and increased infertility. Poor intake of proteins, micro and macro-minerals and vitamins is associated with reduction in reproductive performance since the altered energy balance is directly correlated to the reduced ovulatory maturation in women (17). Thus, inadequate nutrition is closely linked to female reproductive pathophysiology. This is confirmed by the fact that both bulimia nervosa and anorexia, namely two pathologic conditions affecting $5 \%$ of women in childbearing age, are indisputable causes of amenorrhea, infertility and miscarriages (18).

\section{Overweight and Obesity}

Overweight and obesity are diffused pathological conditions during the woman's reproductive age, with an incidence up to 20$25 \%$ among patients consulting for infertility. WHO estimates that $9 \%$ to $25 \%$ of females in industrialized countries are obese and at greater risk of generating obese children, particularly when affected by gestational diabetes. Through insulin resistance (IR) and high levels of insulin and androgens, the adipose tissue is responsible for ovulatory disorders in disposed patients and the anovulation associated to obesity is responsible for higher risk of miscarriages and infertility (19). Management of anovulation in obese women includes diet and exercise in parallel with standard methodologies of ovulation induction.

In patients without ovulatory disorders, overweight and obesity extend the time to conceive, decrease the outcome of infertility treatment and increase the rates of gestational diabetes, hypertension, cesarean section, overweight newborns, perinatal mortality and morbidity. A number of nutritional and clinical studies have confirmed that the Mediterranean Dietary (MedDiet) patterns and regular physical activity in overweight women significantly reduce unsuccessful attempts to conceive and improve the efficacy of ARTpregnancy programs. Therefore, the evaluation of lifestyle habits and the modification of unhealthy behaviors by appropriate assistance or with specific management, such as acid folic supplementation, must be systematic in females attempting to conceive (20).

\section{NUTRITIONAL RELATED DISEASES}

\section{Obesity and Anovulation}

IR and hyperinsulinemia are the primary underlying metabolic abnormalities reported in obesity, which are key features of the Metabolic Syndrome (MS) and PCOS, and have a significant impact on female fertility. Elevated circulating insulin levels and IR provide an unfavorable biochemical environment in the ovaries, increasing both androgen over-synthesis and lipid metabolism from theca cells, that in turn induce a central distribution of fat and dyslipidemia. The android fat distribution pattern may be justified by hyperandrogenism, resulting in a vicious circle of central adiposity, hyperinsulinism, and metabolic aberrations (21). Also, cytokines are highly active in ovarian physiology, where they are involved in the formation of a favorable environment for the selection and growth of the follicle since these molecules are involved in key processes of cell proliferation and differentiation, survival and atresia of the follicle and oocyte development (22). Several cytokines, such as TGF- $\beta$-superfamily members, are involved in all steps of folliculogenesis while the production of others is stagedependent: FGF-2 and VEGF, together with SDF-1a and leptin, are also capable of regulating corpus luteum development and function. In particular, leptin stimulates estrogen synthesis in luteinized granulosa cells and reduces progesterone synthesis in insulin stimulated theca cells. This mechanism also explains infertility related to obesity, an altered metabolic state in which the concentrations of leptin are particularly high (23).

\section{Polycystic Ovary Syndrome (PCOS)}

PCOS is a recurrent reproductive endocrinological disorder that affects up to $20 \%$ of women of reproductive age globally (24). Basic diagnostic criteria for PCOS include at least two of the following criteria: oligo-anovulation, hyperandrogenism and ultrasound-ascertained polycystic morphology of one ovary (minimum 12 follicles of $2-9 \mathrm{~mm}$ in diameter or $\geq 10 \mathrm{~cm}^{3}$ ovarian volume) (24). The IR and hyperinsulinemia play a significant role in the development of PCOS and contribute to the development of MS (25). However, the mechanism by which hyperinsulinemia and hyperandrogenism are responsible for the deregulation of ovarian function is unclear. Experimental data show that through its receptor, insulin has specific activities on steroidogenesis by stimulating the cells of the theca to oversecrete androgens and improving the responsiveness of ovaries to the luteinizing hormone ( $\mathrm{LH}$ ) for the androgen production (26). 
The insulin-like growth factor-I receptor (IGF-IR) could also be involved in the mechanism of hyperandrogenism induced by hyperinsulinemia observed in PCOS patients. In fact, when bound to IGF-IR, the insulin activates $\beta$-subunit tyrosine kinase activity by amplifying the normal IGF-I signal (27). Moreover, the insulin-like growth factor binding proteins (IGFBPs) are involved in the systemic and local regulation of IGF activity by both IGFI and IGFII with high affinity. These complexes thus lead to a reduction in the hepatic secretion of insulin growth-factorbinding protein-I (IGFBP-I) and a consequent bioavailability of IGF-I, with the final effect of enhancing the androgen production by both interstitial and stromal cells of the theca (23) (Figure 1).

Previous studies have established that patients affected by PCOS with BMI in the highest quartile $\left(\geq 30 \mathrm{Kg} / \mathrm{m}^{2}\right)$ have a very high risk of developing MS (28). PCOS is the major cause of infertility due to anovulatory disorders although the anovulation mechanisms are unclear. The anovulation is characterized by an apparent arrest of antral follicle development at the $5-10 \mathrm{~mm}$ developmental stage thus implying a failure in entering the cycle preovulatory phase. Under specific conditions, however, the spontaneous ovulation may also occasionally occur, and the disorder can be reverted in most cases by increasing the FSH serum levels.

PCOS is often accompanied with altered gonadotropin levels, decreased levels of IGF-BP1, increased ovarian 17hydroxiprogesterone (17-OHP) and androgen response to Gonadotropin-Releasing-Hormone agonists (GnRHagonists). PCOS affects about $75 \%$ of women suffering from anovulation-related infertility and its management depends on symptoms. Thus, appropriate therapy for PCOS becomes necessary in order to induce ovulatory cycles and fertility (28).

Metformin is the most commonly used insulin-sensitizing drug to treat PCOS thanks to its ability to increase insulin sensitivity, reduce hepatic gluconeogenesis, as well as to inhibit hepatic uptake of lactate and alanine, and to increase the conversion of pyruvate to alanine. The molecular pathway triggered by Metformin is today partially unclear. Several studies have identified multiple potential mechanisms of action such as the inhibition of the mitochondrial respiratory chain and glycerophosphate dehydrogenase, hyperactivation of AMP-activated protein kinase (AMPK) or cyclic adenosine monophosphate (cAMP), inhibition of glucagon and deregulation of gut microbiota (29). These mechanisms, together or individually, result in an increase of oocyte maturation and a favorable effect on infertility in PCOS. A lower-carbohydrate diet capable of inducing a reduction in insulin production may be a valid-alternative to the drug regimen. In fact, the decrease of carbohydrate uptake downregulates the glucose stimulus to pancreatic $\beta$ cells reducing the amount of secreted insulin. While several studies have explored the correlations between diet quality and weight loss (30), other observations have investigated in weight-stable conditions the possible consequence of diet composition on $\beta$-cell responsiveness and insulin sensitivity $(31,32)$.

\section{Metabolic Syndrome (MS)}

MS is a very common disease in Western countries and includes multiple endocrine disturbances, such as overweight, altered levels of hepatocytolysis, arterial hypertension, obesity, dyslipidemia, and IR. MS is a major social health problem, particularly in developed nations such as the United States but also in Europe, with a prevalence of 20 and 30\%, respectively (33). Although not completely assessed, several factors have been implicated and primarily include the hypercaloric diet in association with deregulated dietary habits, sedentary lifestyles, increased age and augmented BMI. MS is also suspected to play a definite role in carcinogenesis, particularly in the gastrointestinal tract.

Several studies have demonstrated that females with MS, inadequate metabolic control and primary or secondary amenorrhea show low levels of LH and FSH, associated with a lack of residual insulin secretion $(34,35)$. Such studies have demonstrated abnormalities of GnRH pulse generator, as well as a decrease in numbers and amplitude of LH pulses in patients with diabetes and amenorrhea compared to patients with normal menstrual cycles. On the other hand, IR, hyperinsulinemia and related metabolic abnormalities in MS may exert a role in the progress of the PCOS (36).

Interestingly, all therapeutic approaches used for the correction of insulin homeostasis in obese and MS patients, such as Thiazolidinediones, Metformin, lifestyle modification for weight reduction or bariatric surgery have been proven to produce restoring effects on ovulation and hyperandrogenemia (37).

\section{HEALTHY NUTRITION FOR A HEALTHY OVULATION}

Nutrition plays a major role in enhancing the reproductive efficiency both in women and men, and contrarily to the detrimental role of body weight, the effect of the diet in female fertility is not well-defined. However, the interaction between nutrition and fertility appears critical for the reproductive performance and the relationship between ovulatory disorders and metabolic diseases such as diabetes and/or galactosemia suggests that dietary factors exert etiological role in some variants of infertility (34).

A study performed in 2006 on 12,579 subjects from the Southampton Women's Survey has demonstrated that female and male preconceptional nutritional status influences fertility and perinatal conditions $(35,38)$.

This observational prospective study performed on 161 women from the Food, Lifestyle and Fertility Outcome Project has revealed that a diet rich in fish, legumes, vegetables and low in carbohydrates was linearly related with red blood cell folate and vitamin B6 in blood and follicular fluid, with a $40 \%$ increase in the chance of pregnancy by IVF intracytoplasmic sperm injection (ICSI) (36). Similarly, a dietary intake of Polyunsaturated omega-3 fatty acids (FAs), Alpha-linolenic acid and Docosahexaenoic acid (DHA) is related to a positive outcome in women undergoing IVF/ICSI (37). 


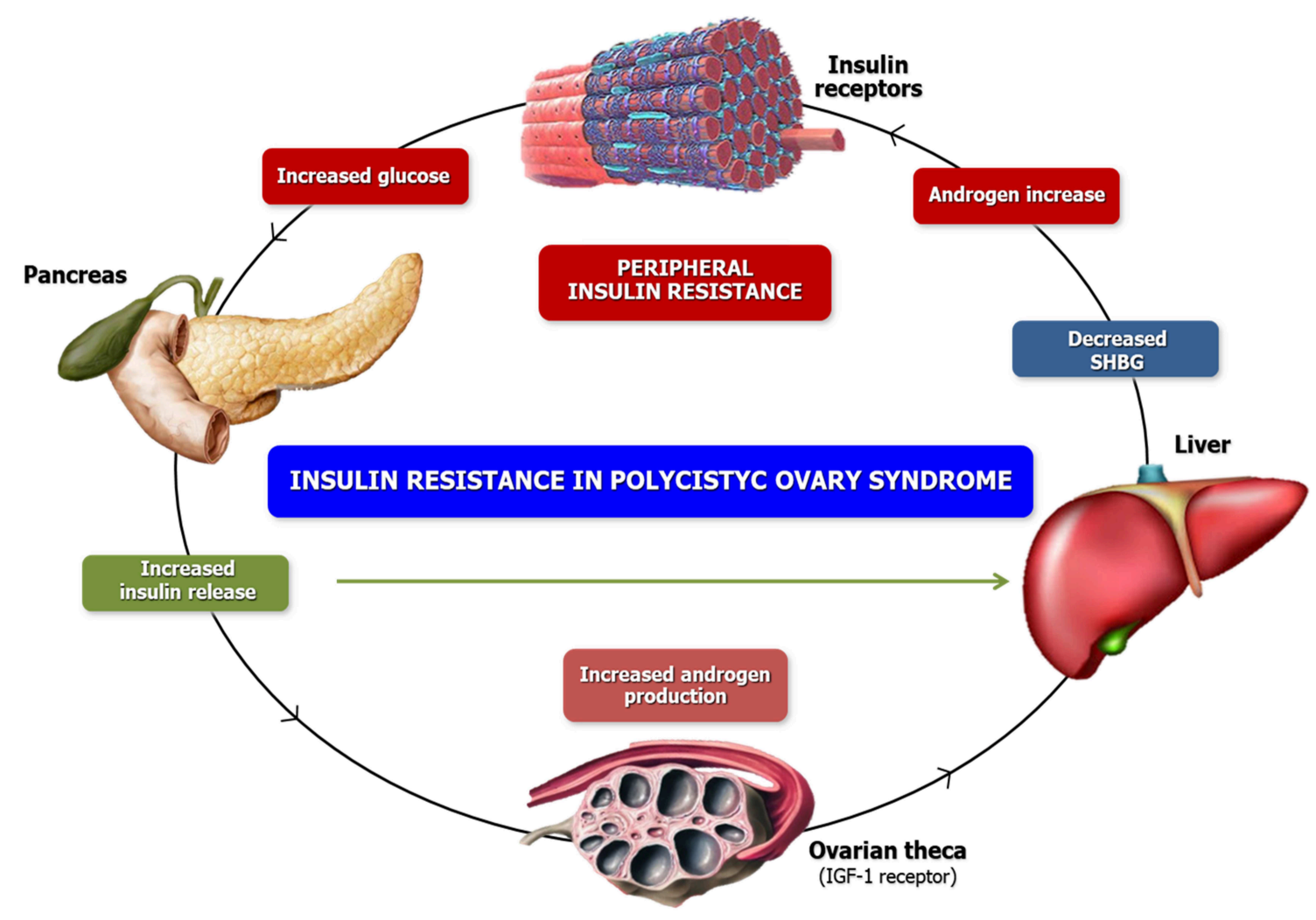

FIGURE 1 | Phatogenesis of Hyperandrogenism. Similar to the high bio-availability of androgens, high insulin concentrations inhibit SHBG production. However, the combined activity of insulin and androgens reduces the SHGB concentrations yielding increased free androgen levels which aggravate the underlying insulin resistance. These conditions ultimately foster a self-propagating positive feed-back loop that increases in severity over time. On the other side, insulin stimulates ovarian androgen production acting via insulin receptors on theca/interstitial cells in ovarian stroma. At high levels, insulin also binds to IGF-1 receptors or possible hybrid receptors, which are structurally similar and use a similar signaling mechanism.

A case-control study on 485 women from the Seguimiento Universidad de Navarra (SUN) Project suggested that reproductive outcomes were improved in couples with a correct balanced diet (39). Although some associations have been identified between periconceptional diet and fertility, the mechanism by which nutritional status can influence implantation, embryo quality and perinatal or child health still remains undefined (40).

The role of different nutrients that could have an impact on female fertility are summarized in the following sections.

\section{Proteins}

The role of protein intake on reproduction is complex and it is still unclear how the source or the amount of protein consumption may affect the ovulatory function or women's fertility. However, it is well-known that protein intake has been associated with a deregulation of the steroidogenesis in women affected by PCOS, likely by reducing hyperinsulinemia. To this regard, Mumford et al. demonstrated that in healthy women a protein-rich diet, particularly of animal proteins, is significantly associated with lower testosterone levels, thus highlighting the potential correlation between protein intake and androgen synthesis (41).
Furthermore, in a cohort of healthy women Chavarro and coworkers, showed that the consumption of animal or vegetable proteins was associated with increased or lower risk of ovulatory infertility, respectively. This correlation is statistically significant in women older than 32 years but the underlying mechanisms remain unclear (42).

\section{Carbohydrates}

To date it is still not well-established whether carbohydrate consumption could have an effect on ovulatory function and in general on fertility in healthy women. In a population of 17,544 women, Chavarro and coworkers showed that the chronic intake of carbohydrates was positively associated with ovulatory disorders (43). In this context, restored ovulatory function and fertility were observed in healthy women with PCOS by improving glucose homeostasis. Thus, it is possible that several ovulatory disorders are caused by the effects of carbohydrate intake on glucose metabolism (44). Therefore, a higher dietary glycemic load appears related with elevated fasting glucose levels, hyperinsulinemia and IR, that are responsible for a higher release of free IGF-I and androgens ultimately resulting in endocrine disturbance and oocyte maturative defects (45). 


\section{Lipids}

The impact of fats on reproduction in women is an actual focus of investigative research. Dietary fatty acids and cholesterol intakes are theorized to affect fertility and pregnancy outcomes, likely through the increased production of prostaglandins and steroids (46). However, few data are available about the relationship between fat intake, androgen levels and ovulation. Mumford and collaborators observed in a group of 259 regularly menstruating women that the total fat intakes of polyunsaturated fatty acids (PUFA) were not associated with higher testosterone levels, but rather with progesterone elevations promoting a decreased risk of anovulation (47).

Therefore, their results suggest a weak role for fatty acids, specifically PUFAs, in androgen synthesis, although future studies are needed to answer the question of whether or not alterations in androgen synthesis may consistently affect the female fertility (47).

\section{Antioxidants}

Oxidative Stress (OS) and the resulting variation of the DNA methylation are capable of impacting reproductive capacity. OS develops from a bodily imbalance between the anti-oxidant protection and free radical (ROS) release (48). Therefore, since diet is a source of exogenous oligo-elements and vitamins, current clinical practice suggests to integrate the diet with some nutritional supplements that are capable to reverse this imbalance, inducing the control of the OS and improving fertility (49). Among several existing antioxidants, Glutathione is a natural compound with a strong detoxifying activity, that maintains the redox state of the cell by limiting the production of free radicals. Other antioxidants include the Lipoic acid, Vitamin E, Vitamin C and CoenzymeQ10 (CoQ10), whose deficiency or altered concentrations, alone or in combination, may definitely impair the function of the whole detoxifying system (50).

The effect of a regular intake of ascorbic acid has been widely described in literature, showing that its consumption during pregnancy could stimulate the human placental/trophoblastic steroidogenesis that physiologically supports gestation (51). In fact, it has also been reported that among women with frequent spontaneous abortions dependent on a luteal phase defect, the blood levels of this antioxidant were lower than in females with better reproductive outcomes (52).

However, although there are many studies supporting the influence of the antioxidants intake on the reproductive capacity, less is known about their action on menstrual function (53). A report from the BioCycle Study described a positive correlation between OS and endogenous estradiol (E2) whereas no association with FSH and sex hormone-binding globulin (SHBG) is described (54). Showell and coworkers reported in their study that despite the beneficial role of antioxidants in reducing the OS, their incorrect or excessive consumption could induce some adverse effects (55) (Table 1).

Therefore, further trials are necessary to investigate the action of antioxidants on the organism in order to improve the reproductive outcome.

\section{Folates}

It is well-known that preconceptional folic acid supplementation (400 $\mu \mathrm{g}$ per day) both improves folate and decreases homocysteine (Hcy) levels in follicular fluid. Supplementation with folic acid, or multivitamins containing folic acid, has been associated to better embryo quality, improved chances of pregnancy and reduced risk of ovulatory infertility (56). However, even if over $80 \%$ of infertile women are responsive to folic acid supplementation and the use of folic acid is more widespread among infertile women than the fertile ones, only $50 \%$ of them correctly use these products during the preconception times (57). To this regard, Murto and coworkers investigated the folate status among infertile and fertile women and showed that the first group has a significantly better folate status than the others, and that infertile patients are more prone to consume folic acid supplements than controls (58). Folates are a group of interconvertible coenzymes that play fundamental roles in DNA synthesis, methylation and protein synthesis. In fact, folate deficiency may alter these synthetic processes resulting in Hcy accumulation and consequent excessive OS and methylation reactions. The DNA methylation is an epigenetic mechanism, able to modify the expression of specific genes without changing the DNA sequence. Also, methylation alters the physical accessibility to the nucleic acids by molecular complexes responsible for gene expression and, therefore, may modify or suppress the gene function. This process is involved in numerous molecular events such as gene transcription, embryonic development, $\mathrm{X}$ chromosome inactivation, genomic imprinting and chromosome stability, and the methylation profile is maintained during cell division. Thus, the relative information is transmitted to the daughter cells independently of the DNA sequence (16).

Three enzymes, namely methylenetetrahydrofolate reductase (MTHFR), methionine synthase (MTR) and methionine synthase reductase (MTRR) exert a major role in both Hcy and folate metabolic pathways (Figure 2).

Recently, two frequent sequence variants of the MTHFR gene, the c.677C>T (p.Ala222Val; rs1801133) and the c.1298A >C (p.Glu429Ala; rs1801131), have been associated with a decreased enzymatic activity and increased Hcy concentrations (59, 60). Nelen and coworkers proved that two months of daily supplementation of $0.5 \mathrm{mg}$ folic acid in females with a history of unexplained frequent miscarriages and homozygous for the MTHFR-gene $677 \mathrm{C}>\mathrm{T}$ mutation reduced their Hcy concentrations (61). Therefore, these studies demonstrate the importance of the nutritional supplementation with folate, especially in infertile patients with MTHFR polymorphisms related to the folate metabolism $(61,62)$.

\section{The 1-C Cycle Support (1-CC)}

Hcy is metabolized into methionine via the 1-CC. From Hcy, Cysteine can be produced via the cystathionine betasynthase pathway (CBS), a source of the 1-CC, and can be utilized for the synthesis of glutathione and hypotaurine. However, in the oocyte and the early embryo the CBS pathway is not expressed (63). To prevent some birth defects, a supplementation with folic acid is recommended during the preconception period and during 
TABLE 1 | Natural antioxidants.

\begin{tabular}{|c|c|c|c|c|}
\hline Molecule & Natural source & Mechanism of action & Target organ & Molecular target \\
\hline Resveratrol & $\begin{array}{l}\text { Red wine, peanut, grape, } \\
\text { pine, blackberry }\end{array}$ & $\begin{array}{l}\text { Anti-proliferative, } \\
\text { anti-angiogenic, } \\
\text { anti-inflammatory }\end{array}$ & $\begin{array}{l}\text { Ovary, breast, prostate, } \\
\text { liver, lung, stomach }\end{array}$ & $\begin{array}{l}\text { P53, glutathione, AKT, } \\
\text { NFkB, iNOS, STAT3, } \\
\text { Survivina }\end{array}$ \\
\hline Lupiol & $\begin{array}{l}\text { Mango, olives, strawberry, } \\
\text { black grapes }\end{array}$ & $\begin{array}{l}\text { Anti-mutagen, } \\
\text { anti-proliferative, } \\
\text { anti-apoptotic }\end{array}$ & $\begin{array}{l}\text { Skin, lung, pancreas, } \\
\text { colon, prostate, liver }\end{array}$ & $\begin{array}{l}\text { P21, Fas, Bcl-2, Bax, AKT, } \\
\text { NFkB, COX-2, NOS,RAS }\end{array}$ \\
\hline Betulinic acid & $\begin{array}{l}\text { Widespread in the } \\
\text { vegetable rank (birch) }\end{array}$ & $\begin{array}{l}\text { Anti-inflammatory, } \\
\text { immunomodulatory, } \\
\text { anti-apoptotic }\end{array}$ & $\begin{array}{l}\text { Skin, ovary, prostate, lung, } \\
\text { breast, kidney, uterine } \\
\text { cervix }\end{array}$ & $\begin{array}{l}\text { PPR-g, p21, p38, NFkB, } \\
\text { JNK, COX-2 }\end{array}$ \\
\hline $\begin{array}{l}\text { Polynsatured Fatty } \\
\text { acids }\end{array}$ & $\begin{array}{l}\text { Corn, sunflower, olives, } \\
\text { spinach, walnuts }\end{array}$ & $\begin{array}{l}\text { Anti-apoptotic, } \\
\text { anti-inflammatory }\end{array}$ & $\begin{array}{l}\text { Colon, breast, prostate, } \\
\text { pancreas, blood tumors }\end{array}$ & $\begin{array}{l}\text { NFkB, Fas/FasL, PPr-g, } \\
\text { Bcl-2, ERK1/2, STAT3 }\end{array}$ \\
\hline Glicolide B & Ginseng & $\begin{array}{l}\text { Anti-angiogenic, } \\
\text { anti-apoptotic }\end{array}$ & Ovary, brain, breast & iNOS, JNK \\
\hline Luteolin & $\begin{array}{l}\text { Artichoke, celery, green } \\
\text { pepper, broccoli, mint }\end{array}$ & $\begin{array}{l}\text { Anti-inflammatory, } \\
\text { anti-allergic, } \\
\text { anti-proliferative }\end{array}$ & $\begin{array}{l}\text { Ovary, liver, colon, breast, } \\
\text { prostate, skin, pancreas }\end{array}$ & $\begin{array}{l}\text { JNK, p53, IGF-1R, EGFR, } \\
\text { BCL-2, STAT3 }\end{array}$ \\
\hline Lycopene & $\begin{array}{l}\text { Tomato, pink grapefruit, } \\
\text { papaya }\end{array}$ & $\begin{array}{l}\text { Anti-proliferative, } \\
\text { anti-inflammatory, } \\
\text { anti-angiogenic }\end{array}$ & $\begin{array}{l}\text { Lung, breast, pancreas, } \\
\text { colon }\end{array}$ & $\begin{array}{l}\text { Ciclina D1, Bcl-2, AKT, } \\
\text { NFkB }\end{array}$ \\
\hline
\end{tabular}

An incomplete list with origin and molecular effects on target organs.

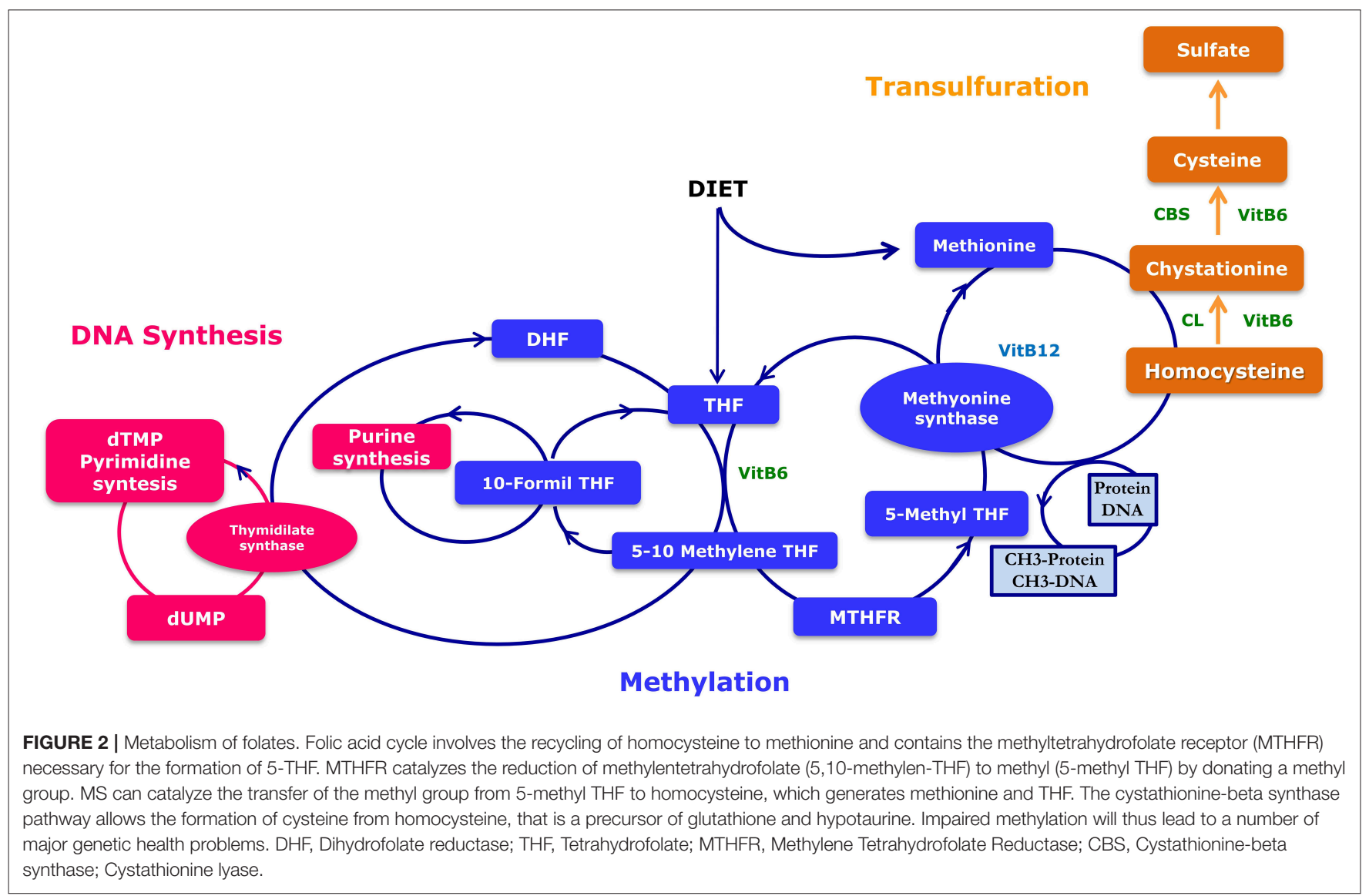

the first trimester of pregnancy. Guidelines recommend a daily intake of $400 \mu \mathrm{g}$ of folic acid during the preconception period and during the first trimester of pregnancy to prevent neural tube defects (NTDs) (64). The MTHFR 677C-T variant, detected with a frequency of up to $15 \%$ in female population, encodes for a less efficient protein in Hcy catabolism. Therefore, in patients 
carrying this variant, folic acid may generate its negative feedback effect, determining a block of the folic acid cycle. Cornet and coworkers reported the beneficial effect of the nutritional support based on supplementation of the 1-CC in subfertile couples having failed previous ARTs (49).

\section{THE MEDITERRANEAN DIET (MEDDIET)}

The MedDiet is a healthy eating plan inspired by the nutritional regime of the populations of Greece, Southern Italy, and Spain in the fifties of the twentieth century. The main features of this diet are high amount of legumes, vegetables and fruits, olive oil, unrefined cereals, moderate to high consumption of fish, wine and low intake of meat.

A systematic review and meta-analysis performed in 2011 on 13,800 cancer patients and 23,340 healthy controls reported that adherence to the MedDiet was related to a reduced risk of death from cancer and specifically that the regular consumption of olive oil may reduce the probability of cancer (65).

A 2013 Cochrane review performed on 52,044 randomized participants showed limited positive effects of the MedDiet on cardiovascular risk (66), whereas in the same year a metaanalysis performed on 3,073 randomly assigned individuals with different dietary regimes showed that the MedDiet as well as diets characterized by low-glycemic index, low-carbohydrate and high-protein determined an improvement in cardiovascular risk factors in patients with diabetes (67).

More recently, a huge umbrella review conducted on more than $12,800,000$ subjects from 29 meta-analyses demonstrated a robust statistical association between adherence

TABLE 2 | Results and recommendations of the Nurses' Health Study II (NHSII) to reduce the risk of infertility due to ovulatory disorders.

\begin{tabular}{|c|c|c|}
\hline & $\begin{array}{l}\text { Risk of ovulatory } \\
\text { infertility (\%) }\end{array}$ & $\begin{array}{l}\text { Recommendations NHSII } \\
\text { "Mediterranean diet" }\end{array}$ \\
\hline Carbohydrates & 1.90 & $\begin{array}{l}\text { Decrease the glucides at high } \\
\text { glycemic }\end{array}$ \\
\hline Lipids & 1.79 & $\begin{array}{l}\text { Consume a portion a day of products } \\
\text { rich in fat }\end{array}$ \\
\hline Protein & $\begin{array}{l}1.41 \\
0.78\end{array}$ & $\begin{array}{l}2 \% \text { Increase in the intake of } \\
\text { polynsatured fatty acids } \\
2 \% \text { Increase in the intake of } \\
\text { monounsatured fatty acids }\end{array}$ \\
\hline Folates & 0.59 & $\begin{array}{l}\text { Consume vitamin supplements: B6, } \\
\text { B9, and B12 }\end{array}$ \\
\hline Iron & 0.60 & $\begin{array}{l}\text { Consume nutritional supplements of } \\
\text { iron }\end{array}$ \\
\hline
\end{tabular}

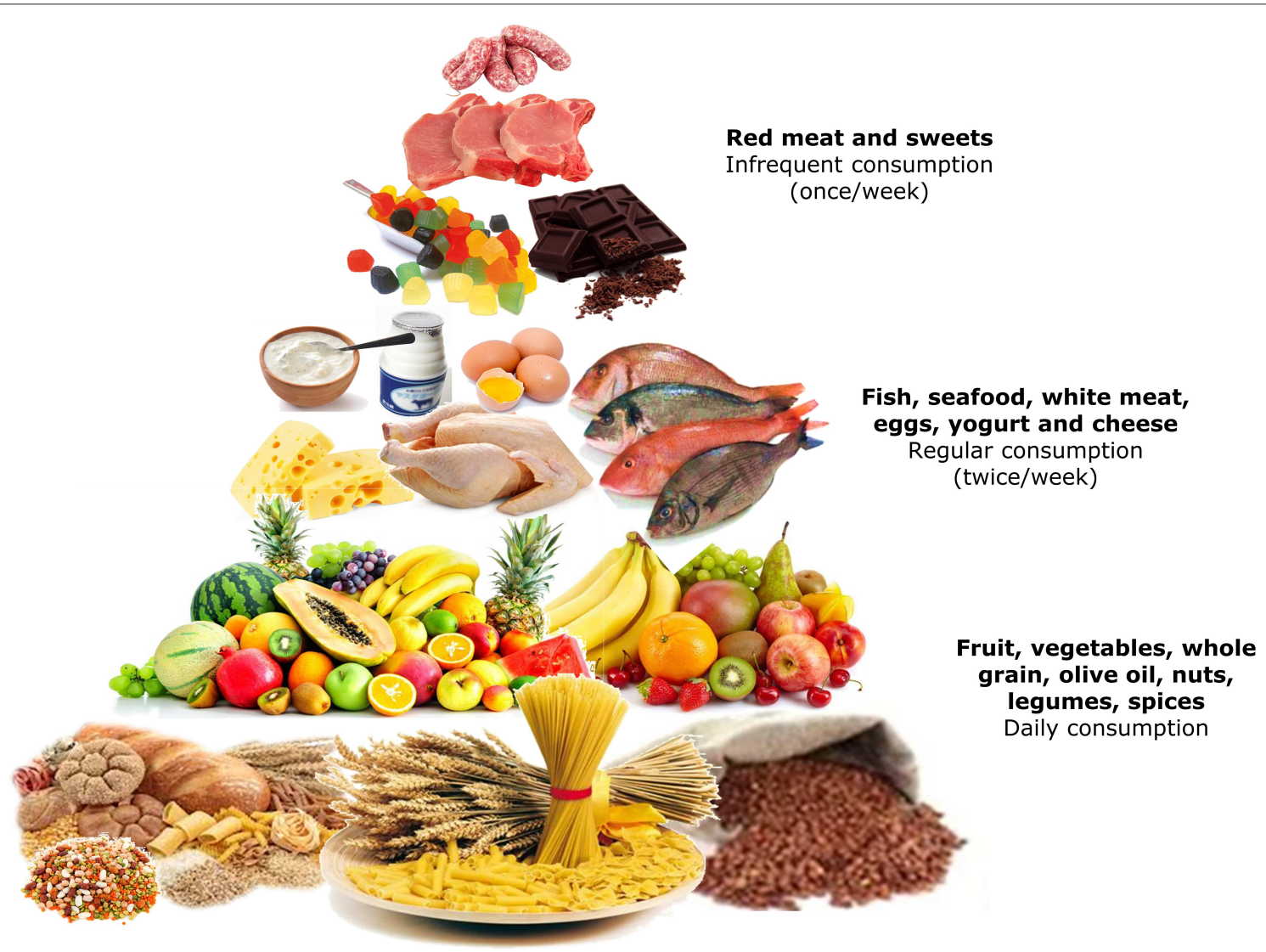

FIGURE 3 | The Mediterranean pyramid of nutrition style and weekly organization of meals. 
to the MedDiet and risk reduction of cardiovascular and neurodegenerative diseases, cancer incidence and diabetes (68) (Figure 3).

Recently, several studies showed that different diets in preconception may impact IVF outcomes, and the MedDiet was positively related with folate and vitamin B6 in blood and follicular fluid levels, with a $40 \%$ increase in the possibility of pregnancy (36). Karayiannis and colleagues, evaluated the influence of the MedDiet on a better IVF performance in women attempting pregnancy (69) (Table 2) and found that there was no association between MedDiet and the outcomes of IVF or the frequency of implantation. However, MedDiet score was positively related to clinical pregnancy and live birth in particular in women of $<35$ years old with respect to the older ones $(P \leq 0.01)$. Furthermore, a beneficial 5-point increase in MedDiet score in the same group of women (<35 years), was associated with a 2.7fold higher probability of achieving clinical pregnancy and live birth, thus proving the efficacy of the MedDiet in preserving the female reproductive health (70). However, the molecular mechanisms underlying both cellular and molecular mechanisms of the relationship between the nutritional regimen and embryo quality, implantation, periconceptional and perinatal development, are presently under intensive investigation.

In a prospective association study on the consumption of polyunsaturated fatty acids, Hammiche F. and collaborators, observed a significant correlation among embryo morphology after IVF and dietary intake of the Omega-3 fatty acids (Fas), Alpha-linolenic acid and Docosahexaenoic acid (DHA) and embryo morphology after IVF (37). Moreover, Yang and coworkers demonstrated that high fat diets resulted in lipid accumulation and endoplasmic reticulum (ER) stress in oocytes in rodents, while the lower folate levels in follicular fluids correlated to poor embryo quality (71). However, to date no large studies have suggested optimized periconceptional diets for fertility outcomes, neither for perinatal or child health outcomes (40).

Other investigators are defining how a modification of the diet for 6 weeks may have favorable effects on developing oocytes and sperms, or for embryo implantation. These authors suggest that blood and follicular biomarkers, useful for evaluating the embryo quality in terms of implantation potential, can be identified and analyzed at the time of oocyte retrieval in IVF (72).

This study also aims to investigate the glucose and the amino acid content of human endometrial fluid, to elucidate whether a diet rich in omega-3 and Vitamin D may significantly improve embryo development. Therefore, this study will be the first prospective randomized controlled trial in humans examining the effects of dietary intervention on the embryo quality (PREPARE Trial) (72). In conclusion, despite the benefits of the MedDiet in both the management and evolution of some clinical conditions and in IVF outcomes, it is still not easy to translate this type of nutrition to daily clinical practice aimed at improving the health conditions (73).

\section{HOW TO IMPROVE FEMALE FERTILITY WITH A PROPER DIETARY REGIMEN AND ORAL SUPPLEMENTATION}

Several ovulatory disorders are directly linked to metabolic pathologies such as diabetes and galactosemia, suggesting that dietary factors may play an etiological role in some types of infertility, whereas the role of nutrition in female fertility is still unexplored.

Nevertheless, there are few studies available to date on the role of different nutrients on fertility. Most of the available data are from the Nurses' Health Study cohort and are based on a subsample of 18,555 married women with no history of infertility who desired or achieved pregnancy over an 8-year follow-up period (45). Of these women, 438 reported infertility related to ovulation disorders. In this population, diet was evaluated by a survey on food consumption that provided an estimate of the intake of different nutrients, vitamins, minerals, and fiber. The results showed significative association between female fertility and food behaviors including: consumption of lowglycemic carbohydrates, monounsaturated fatty acids, proteins of plant origin and supplementation with iron, folate and vitamins with antioxidant effect (Table 2). The adherence to this type of MedDiet is associated with a lower risk of infertility related to ovulatory disorders and it has been thus estimated that a healthy diet, combined with a sufficient intake of antioxidants, body weight control and regular physical activity, reduces $69 \%$ of the risk of ovulatory infertility. A new topic of increasing interest is the role of the dietary antioxidant consumption, based on the evidence of an experimental correlation between low antioxidant status and known and idiopathic infertility (45). In this contest, Ruder E.H. and coworkers, in their study exploring 437 couples treated for unexplained infertility, showed that a higher ingestion of antioxidants ( $\beta$-carotene, Vitamins $\mathrm{C}$ and $\mathrm{E}$ ) was related to a shorter time to pregnancy (74).

\section{The Oral Supplementation Against the Endocrine Disruptors}

Animal studies have demonstrated that an appropriate dietary assumption of methyl donor supplements can reduce the effects of environmental endocrine disrupting chemicals (EDCs). EDCs are usually components of cosmetics and "domestic use" products. They induce abnormal effects on methylation profiles and regulatory epigenetic mechanisms in their transgenerational transmission. In animal models, plastic products such as Bisphenol A (BPA), Di(2-ethylhexyl)phthalate (DEHP), and Dibutyl phthalate (DBP) induce transgenerational reproductive and metabolic pathologies. The relation between EDCs, OS, and DNA methylation abnormalities is now well-recognized, namely EDCs generate OS through estrogen receptors and peroxisome proliferator-activated receptors (75).

BPA has a strong structural similarity with Diethylstilbestrol and E2. Human epidemiological studies have recently highlighted the presence of BPA, parabens, and other organic pollutants in the urine or serum of women who have difficulty in conceiving and/or suffer early menopause. Experiments 


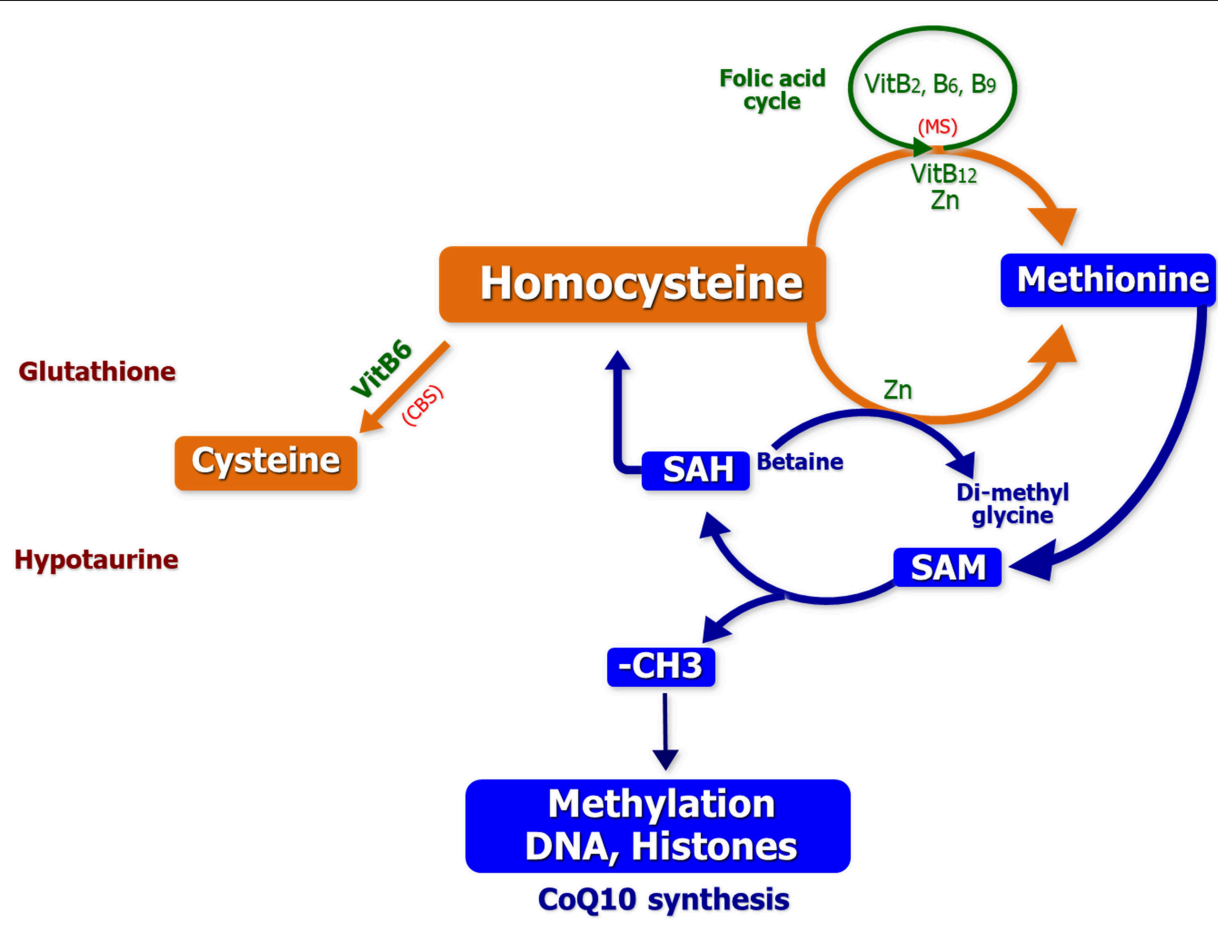

FIGURE 4 | The one carbon cycle: contribution to methylation process and genesis of major antioxidant molecules (76).

in the Avy/a (yellow) mouse have shown that methyl donor supplements (support of the 1-CC) definitely affect gene expression and counteract the hypomethylation effects of BPA. As already mentioned above, the 1-CC is involved in the methylation processes, by recycling Hyc, and the generation of endogenous antioxidants such as glutathione and hypotaurine, as well as CoQ10, capable of modulating epigenetic settings in association with Vitamins B2 and B3 (Figure 4) (77). In a recent clinical study, our group proved the efficacy of the 1-CC support in subfertile couples to counteract the negative effects of the environment. In fact, a cohort of 55 women with a history of 3-7 years of sterility, with at least 2 failed ART procedures, and low serum levels of $\mathrm{AMH}$, were treated with 1-CC supplement for 4 months. Surprisingly, we observed 8 spontaneous conceptions within 3 months (76). Therefore, as observed in animal models, an adequate nutritional support of 1-CC can at least in part improve the environmental metabolic derangements causing ovary related infertility (76).

\section{CONCLUSIONS}

Female infertility is a global medical and social condition caused by various pathophysiological alterations. In a remarkable number of cases the pathogenesis is not clearly defined, determining indecision concerning the most appropriate treatment choices. While in developing countries this condition is related to preventive, diagnostic and therapeutic inadequacy, multiple ovarian endocrine dysfunctions in industrialized nations are apparently associated with improper life-styles.
In this context, IR appears as a major pathogenic mechanism impairing the physiology of ovulatory functions, while an adequate intake of monounsaturated fatty acids from vegetables may be effective in the prevention of female infertility. Adequate intake of antioxidants also supports female reproductive functions since the dietary supplements containing folic acid, $\beta$-carotene, Vitamin $\mathrm{C}$ and $\mathrm{E}$, and an adequate nutritional support of the 1-CC are definitely efficient in shortening the time to conception.

In conclusion, a correct balance of proteins, carbohydrates, lipids, antioxidant and folate in the daily diet provides essential benefit for an optimal female reproductive health and reduces the risk of infertility. In this context, the association of MedDiet with antioxidants compounds and 1-CC support appears suitable to improve women's fertility.

\section{AUTHOR CONTRIBUTIONS}

This review is the result of the contributions of all authors. ES and RP were responsible for literature research, synthesis, and summarization of results. DL analyzed data and drafted the manuscript. ES had primary responsibility for final content. All authors read and approved the final manuscript.

\section{FUNDING}

This work was supported by the AIRC Associazione Italiana per la Ricerca sul Cancro [grant number 17536] and from the Apulia Region (Oncogenomic Project and Jonico-Salentino Project). 


\section{REFERENCES}

1. Habbema JD, Collins J, Leridon H, Evers JL, Lunenfeld B, te Velde ER. Towards less confusing terminology in reproductive medicine: a proposal. Hum Reproduc. (2004) 19:1497-501. doi: 10.1093/humrep/ deh303

2. Ombelet W, Cooke I, Dyer S, Serour G, Devroey P. Infertility and the provision of infertility medical services in developing countries. Hum Reproduc Update. (2008) 14:605-21. doi: 10.1093/humupd/ dmn042

3. Anderson K, Nisenblat V, Norman R. Lifestyle factors in people seeking infertility treatment - a review. Austr N Zeal J Obstetr Gynaecol. (2010) 50:8-20. doi: 10.1111/j.1479-828X.2009.01119.x

4. Vander Borght M, Wyns C. Fertility and infertility: definition and epidemiology. Clin Biochem. (2018) 62:2-10. doi: 10.1016/j.clinbiochem.2018.03.012

5. Firns S, Cruzat VF, Keane KN, Joesbury KA, Lee AH, Newsholme P, et al. The effect of cigarette smoking, alcohol consumption and fruit and vegetable consumption on IVF outcomes: a review and presentation of original data. Reproduc Biol Endocrinol. (2015) 13:134. doi: 10.1186/s12958-0150133-x

6. Dorfman SF. Tobacco and fertility: our responsibilities. Fertility Steril. (2008) 89:502-4. doi: 10.1016/j.fertnstert.2008.01.011

7. Kunzle R, Mueller MD, Hanggi W, Birkhauser MH, Drescher $H$, Bersinger NA. Semen quality of male smokers and nonsmokers in infertile couples. Fertility Steril. (2003) 79:287-91. doi: 10.1016/S0015-0282(02) 04664-2

8. de Jong AM, Menkveld R, Lens JW, Nienhuis SE, Rhemrev JP. Effect of alcohol intake and cigarette smoking on sperm parameters and pregnancy. Andrologia. (2014) 46:112-7. doi: 10.1111/and.12054

9. Mutsaerts MA, Groen H, Huiting HG, Kuchenbecker WK, Sauer PJ, Land JA, et al. The influence of maternal and paternal factors on time to pregnancy-a Dutch population-based birth-cohort study: the GECKO Drenthe study. Hum Reproduc. (2012) 27:583-93. doi: 10.1093/humrep/der429

10. Oostingh EC, Hall J, Koster MPH, Grace B, Jauniaux E, Steegers-Theunissen RPM. The impact of maternal lifestyle factors on periconception outcomes: a systematic review of observational studies. Reproduc Biomed Online. (2019) 38:77-94. doi: 10.1016/j.rbmo.2018.09.015

11. Klonoff-Cohen H, Natarajan L. The concerns during assisted reproductive technologies (CART) scale and pregnancy outcomes. Fertility Steril. (2004) 81:982-8. doi: 10.1016/j.fertnstert.2003.08.050

12. Purewal S, Chapman SCE, van den Akker OBA. depression and state anxiety scores during assisted reproductive treatment are associated with outcome: a meta-analysis. Reproduc Biomed Online. (2018) 36:646-57. doi: 10.1016/j.rbmo.2018.03.010

13. Domar AD. Stress and infertility in women: Is there a relationship? Psychother Prac. (1996) 2:17-27. doi: 10.1002/(SICI)1520-6572(199622)2:2<17::AIDSESS3 $>3.0$.CO;2-5

14. Miller N, Herzberger EH, Pasternak Y, Klement AH, Shavit T, Yaniv RT, et al. Does stress affect IVF outcomes? A prospective study assessing cortisol levels and stress questionnaires for women undergoing through IVF treatments. Reproduc Biomed Online. (2019) S1472-6483(19)30062-8. doi: 10.1016/j.rbmo.2019.01.012

15. Rich-Edwards JW, Goldman MB, Willett WC, Hunter DJ, Stampfer MJ, Colditz GA, et al. Adolescent body mass index and infertility caused by ovulatory disorder. Am J Obstetr Gynecol. (1994) 171:171-7. doi: 10.1016/0002-9378(94)90465-0

16. Sivestris E, Cohen M, Menezo Y. Oxidative stress (OS) and DNA methylation errors in reproduction. A place for a support of the one carbon cycle (1-C cycle) before conception. Womens Health Gynecol. (2016) 2:30.

17. Jokela M, Elovainio M, Kivimäki M. Lower fertility associated with obesity and underweight: the US National Longitudinal Survey of Youth. Am J Clin Nutr. (2008) 88:886-93. doi: 10.1093/ajcn/88.4.886

18. Group ECW. Nutrition and reproduction in women. Hum Reproduc Update. (2006) 12:193-207. doi: 10.1093/humupd/dmk003

19. WHO. Obesity and Overweight. Geneva (2013).

20. Bellver J, Ayllon Y, Ferrando M, Melo M, Goyri E, Pellicer A, et al. Female obesity impairs in vitro fertilization outcome without affecting embryo quality. Fertility Steril. (2010) 93:447-54. doi: 10.1016/j.fertnstert.2008. 12.032
21. Amudha MR, S.; Kannan, K.; Manavalan, R.;. An updated overview on causes, diagnosis and management of infertility. Int J Pharmacy Sci Revised Res. (2013) 18:155-64. Available online at: http://globalresearchonline.net/ journalcontents/v18-1/23.pdf

22. Field SL, Dasgupta $T$, Cummings $M$, Orsi NM. Cytokines in ovarian folliculogenesis, oocyte maturation and luteinisation. Mol Reproduc Dev. (2014) 81:284-314. doi: 10.1002/mrd. 22285

23. Silvestris E, de Pergola G, Rosania R, Loverro G. Obesity as disruptor of the female fertility. Reproduc Biol Endocrinol. (2018) 16:22. doi: 10.1186/s12958-018-0336-Z

24. Azziz R, Carmina E, Chen Z, Dunaif A, Laven JS, Legro RS, et al. Polycystic ovary syndrome. Nat Rev Dis Primers. (2016) 2:16057. doi: $10.1038 /$ nrdp. 2016.58

25. Amato MC, Vesco R, Vigneri E, Ciresi A, Giordano C. Hyperinsulinism and polycystic ovary syndrome (PCOS): role of insulin clearance. $J$ Endocrinol Invest. (2015) 38:1319-26. doi: 10.1007/s40618-0150372-X

26. Hillier SG. Current concepts of the roles of follicle stimulating hormone and luteinizing hormone in folliculogenesis. Hum Reproduc. (1994) 9:188-91. doi: 10.1093/oxfordjournals.humrep.a138480

27. Poretsky L, Grigorescu F, Seibel M, Moses AC, Flier JS. Distribution and characterization of insulin and insulin-like growth factor I receptors in normal human ovary. J Clin Endocrinol Metabol. (1985) 61:728-34. doi: 10.1210/jcem-61-4-728

28. Polak K, Czyzyk A, Simoncini T, Meczekalski B. New markers of insulin resistance in polycystic ovary syndrome. J Endocrinol Invest. (2017) 40:1-8. doi: 10.1007/s40618-016-0523-8

29. Collier CA, Bruce CR, Smith AC, Lopaschuk G, Dyck DJ. Metformin counters the insulin-induced suppression of fatty acid oxidation and stimulation of triacylglycerol storage in rodent skeletal muscle. Am J Physiol Endocrinol Metabol. (2006) 291:E182-9. doi: 10.1152/ajpendo.00272. 2005

30. Clark AM, Ledger W, Galletly C, Tomlinson L, Blaney F, Wang X, et al. Weight loss results in significant improvement in pregnancy and ovulation rates in anovulatory obese women. Hum Reproduc. (1995) 10:2705-12. doi: 10.1093/oxfordjournals.humrep.a135772

31. Kiddy DS, Hamilton-Fairley D, Bush A, Short F, Anyaoku V, Reed $\mathrm{MJ}$, et al. Improvement in endocrine and ovarian function during dietary treatment of obese women with polycystic ovary syndrome. Clin Endocrinol. (1992) 36:105-11. doi: 10.1111/j.1365-2265.1992. tb02909.x

32. Gower BA, Chandler-Laney PC, Ovalle F, Goree LL, Azziz R, Desmond RA, et al. Favourable metabolic effects of a eucaloric lower-carbohydrate diet in women with PCOS. Clin Endocrinol. (2013) 79:550-7. doi: 10.1111/cen.12175

33. Shahini N, Shahini I, Marjani A. Prevalence of metabolic syndrome in turkmen ethnic groups in gorgan. J Clin Diagn Res. (2013) 7:1849-51. doi: 10.7860/JCDR/2013/6035.3331

34. Livshits A, Seidman DS. Fertility issues in women with diabetes. Women's Health. (2009) 5:701-7. doi: 10.2217/WHE.09.47

35. Iniguez G, Torrealba IM, Avila A, Cassorla F, Codner E. Adiponectin serum levels and their relationships to androgen concentrations and ovarian volume during puberty in girls with type 1 diabetes mellitus. Hormone Res. (2008) 70:112-7. doi: 10.1159/000137656

36. Vujkovic M, de Vries JH, Lindemans J, Macklon NS, van der Spek PJ, Steegers EA, et al. The preconception Mediterranean dietary pattern in couples undergoing in vitro fertilization/intracytoplasmic sperm injection treatment increases the chance of pregnancy. Fertility Steril. (2010) 94:2096101. doi: 10.1016/j.fertnstert.2009.12.079

37. Hammiche F, Vujkovic M, Wijburg W, de Vries JH, Macklon NS, Laven JS, et al. Increased preconception omega-3 polyunsaturated fatty acid intake improves embryo morphology. Fertility Steril. (2011) 95:1820-3. doi: 10.1016/j.fertnstert.2010.11.021

38. Inskip HM, Godfrey KM, Robinson SM, Law CM, Barker DJ, Cooper C, et al. Cohort profile: the Southampton Women's Survey. Int J Epidemiol. (2006) 35:42-8. doi: 10.1093/ije/dyi202

39. Toledo E, Lopez-del Burgo C, Ruiz-Zambrana A, Donazar M, NavarroBlasco I, Martinez-Gonzalez MA, et al. Dietary patterns and difficulty conceiving: a nested case-control study. Fertility Steril. (2011) 96:1149-53. doi: 10.1016/j.fertnstert.2011.08.034 
40. Anderson K, Norman RJ, Middleton P. Preconception lifestyle advice for people with subfertility. Cochr Database Syst Rev. (2010) 4:CD008189. doi: 10.1002/14651858.CD008189.pub2

41. Mumford SL, Alohali A, Wactawski-Wende J. Dietary protein intake and reproductive hormones and ovulation: the BioCycle study. Fertility Steril. (2015) 104:e2. doi: 10.1016/j.fertnstert.2015. 07.005

42. Chavarro JE, Rich-Edwards JW, Rosner BA, Willett WC. Protein intake and ovulatory infertility. Am J Obstetr Gynecol. (2008) 198:210 e1-7. doi: 10.1016/j.ajog.2007.06.057

43. Chavarro JE, Rich-Edwards JW, Rosner BA, Willett WC. Diet and lifestyle in the prevention of ovulatory disorder infertility. Obstetr Gynecol. (2007) 110:1050-8. doi: 10.1097/01.AOG.0000287293. 25465.e1

44. Mioni R, Chiarelli S, Xamin N, Zuliani L, Granzotto M, Mozzanega $\mathrm{B}$, et al. Evidence for the presence of glucose transporter 4 in the endometrium and its regulation in polycystic ovary syndrome patients. J Clin Endocrinol Metabol. (2004) 89:4089-96. doi: 10.1210/jc.2003032028

45. Chavarro JE, Rich-Edwards JW, Rosner BA, Willett WC. A prospective study of dietary carbohydrate quantity and quality in relation to risk of ovulatory infertility. Eur J Clin Nutr. (2009) 63:78-86. doi: 10.1038/sj.ejcn. 1602904

46. Saldeen $\mathrm{P}$, Saldeen $\mathrm{T}$. Women and omega-3 Fatty acids. Obstetr Gynecol Survey. (2004) 59:722-30; quiz 45-6. doi: 10.1097/01.ogx.0000140038.70473.96

47. Mumford SL, Chavarro JE, Zhang C, Perkins NJ, Sjaarda LA, Pollack AZ, et al. Dietary fat intake and reproductive hormone concentrations and ovulation in regularly menstruating women. Am J Clin Nutr. (2016) 103:868-77. doi: 10.3945/ajcn.115.119321

48. Ferroni P, Barbanti P, Della-Morte D, Palmirotta R, Jirillo E, Guadagni F. Redox mechanisms in migraine: novel therapeutics and dietary interventions. Antioxidants Redox Signal. (2018) 28:1144-83. doi: 10.1089/ars. 2017.7260

49. Cornet D, Amar E, Cohen M, Ménézo Y. Clinical evidence for the importance of 1-carbon cycle support in subfertile couples. Austin J Reprod Med Infertil. (2015) 2:1011. Available online at: https://www.researchgate.net/profile/ Yves_Menezo/publication/278381279_Austin_Journal_of_Reproductive_ Medicine_Infertility/links/59dce0d30f7e9bdd752dd6a5/Austin-Journal-ofReproductive-Medicine-Infertility.pdf

50. Birben E, Sahiner UM, Sackesen C, Erzurum S, Kalayci O. Oxidative stress and antioxidant defense. World Allergy Organ J. (2012) 5:9-19. doi: 10.1097/WOX.0b013e3182439613

51. Wu X, Iguchi T, Itoh N, Okamoto K, Takagi T, Tanaka K, et al. Ascorbic acid transported by sodium-dependent vitamin $\mathrm{C}$ transporter 2 stimulates steroidogenesis in human choriocarcinoma cells. Endocrinology. (2008) 149:73-83. doi: 10.1210/en.2007-0262

52. Vural P, Akgul C, Yildirim A, Canbaz M. Antioxidant defence in recurrent abortion. Clin Chim Acta Int J Clin Chem. (2000) 295:169-77. doi: 10.1016/S0009-8981(99)00255-7

53. Mayne ST, Wright ME, Cartmel B. Assessment of antioxidant nutrient intake and status for epidemiologic research. J Nutr. (2004) 134:3199S-200S. doi: $10.1093 /$ jn/134.11.3199S

54. Schisterman EF, Gaskins AJ, Mumford SL, Browne RW, Yeung E, Trevisan $\mathrm{M}$, et al. Influence of endogenous reproductive hormones on F2-isoprostane levels in premenopausal women: the BioCycle Study. Am J Epidemiol. (2010) 172:430-9. doi: 10.1093/aje/kwq131

55. Showell MG, Brown J, Clarke J, Hart RJ. Antioxidants for female subfertility. Cochr Database Syst Rev. (2013) 8:CD007807. doi: 10.1002/14651858.CD007807.pub2

56. Chavarro JE, Rich-Edwards JW, Rosner BA, Willett WC. Use of multivitamins, intake of B vitamins, and risk of ovulatory infertility. Fertility Steril. (2008) 89:668-76. doi: 10.1016/j.fertnstert.2007.03.089

57. Nouri K, Walch K, Weghofer A, Imhof M, Egarter C, Ott J. The Impact of a Standardized oral multinutrient supplementation on embryo quality in in vitro fertilization/intracytoplasmic sperm injection: a prospective randomized trial. Gynecol Obstetr Invest. (2017) 82:8-14. doi: $10.1159 / 000452662$
58. Murto T, Skoog Svanberg A, Yngve A, Nilsson TK, Altmae S, Wanggren $\mathrm{K}$, et al. Folic acid supplementation and IVF pregnancy outcome in women with unexplained infertility. Reproduc Biomed Online. (2014) 28:766-72. doi: 10.1016/j.rbmo.2014.01.017

59. Palmirotta R, Lovero D, Silvestris E, Simone V, Lanotte L, Quaresmini D, et al. Characterization of a rare nonpathogenic methylenetetrahydrofolatereductase (MTHFR) gene mutation p.Lys215del in a southern italian family. Hum. Mutat. (2017) 38:120-1. doi: 10.1002/humu.23132

60. Murto T, Yngve A, Skoog Svanberg A, Altmae S, Salumets A, Wanggren $\mathrm{K}$, et al. Compliance to the recommended use of folic acid supplements for women in Sweden is higher among those under treatment for infertility than among fertile controls and is also related to socioeconomic status and lifestyle. Food Nutr Res. (2017) 61:1334483. doi: 10.1080/16546628.2017. 1334483

61. Nelen WL, Blom HJ, Thomas CM, Steegers EA, Boers GH, Eskes TK. Methylenetetrahydrofolate reductase polymorphism affects the change in homocysteine and folate concentrations resulting from low dose folic acid supplementation in women with unexplained recurrent miscarriages. J Nutr. (1998) 128:1336-41. doi: 10.1093/jn/128. 8.1336

62. Palmirotta R, Carella C, Silvestris E, Cives M, Stucci SL, Tucci M, et al. SNPs in predicting clinical efficacy and toxicity of chemotherapy: walking through the quicksand. Oncotarget. (2018) 9:25355-82. doi: 10.18632/oncotarget. 25256

63. Menezo Y, Lichtblau I, Elder K. New insights into human pre-implantation metabolism in vivo and in vitro. J Assist Reproduc Genet. (2013) 30:293-303. doi: 10.1007/s10815-013-9953-9

64. Toivonen KI, Lacroix E, Flynn M, Ronksley PE, Oinonen KA, Metcalfe A, et al. Folic acid supplementation during the preconception period: a systematic review and meta-analysis. Prevent Med. (2018) 114:1-17. doi: 10.1016/j.ypmed.2018.05.023

65. Psaltopoulou T, Kosti RI, Haidopoulos D, Dimopoulos M, Panagiotakos DB. Olive oil intake is inversely related to cancer prevalence: a systematic review and a meta-analysis of 13,800 patients and 23,340 controls in 19 observational studies. Lipids Health Dis. (2011) 10:127. doi: 10.1186/1476-511X10-127

66. Rees K, Hartley L, Flowers N, Clarke A, Hooper L, Thorogood M, et al. 'Mediterranean' dietary pattern for the primary prevention of cardiovascular disease. Cochr Database Syst Rev. (2013) 8:CD009825. doi: 10.1002/14651858.CD009825.pub2

67. Ajala O, English P, Pinkney J. Systematic review and meta-analysis of different dietary approaches to the management of type 2 diabetes. Am J Clin Nutr. (2013) 97:505-16. doi: 10.3945/ajcn.112.042457

68. Dinu M, Pagliai G, Casini A, Sofi F. Mediterranean diet and multiple health outcomes: an umbrella review of meta-analyses of observational studies and randomised trials. Eur J Clin Nutr. (2018) 72:30-43. doi: 10.1038/ejcn. 2017.58

69. Karayiannis D, Kontogianni MD, Mendorou C, Mastrominas M, Yiannakouris N. Adherence to the Mediterranean diet and IVF success rate among non-obese women attempting fertility. Hum Reproduc. (2018) 33:494-502. doi: 10.1093/humrep/dey003

70. Godman H. Adopt a Mediterranean Diet Now for Better Health Later. Boston, MA: Harvard Health Publishing (2013).

71. Yang $\mathrm{X}, \mathrm{Wu} \mathrm{LL}$, Chura LR, Liang $\mathrm{X}$, Lane $\mathrm{M}$, Norman RJ, et al. Exposure to lipid-rich follicular fluid is associated with endoplasmic reticulum stress and impaired oocyte maturation in cumulus-oocyte complexes. Fertility Steril. (2012) 97:1438-43. doi: 10.1016/j.fertnstert.2012. 02.034

72. Kermack AJ, Calder PC, Houghton FD, Godfrey KM, Macklon NS. A randomised controlled trial of a preconceptional dietary intervention in women undergoing IVF treatment (PREPARE trial). BMC Women's Health. (2014) 14:130. doi: 10.1186/1472-687414-130

73. Lacatusu CM, Grigorescu ED, Floria M, Onofriescu A, Mihai BM. The Mediterranean Diet: from an environment-driven food culture to an emerging medical prescription. Int J Environ Res Public Health. (2019) 16:E942. doi: 10.3390/ijerph16060942 
74. Ruder EH, Hartman TJ, Reindollar RH, Goldman MB. Female dietary antioxidant intake and time to pregnancy among couples treated for unexplained infertility. Fertility Steril. (2014) 101:759-66. doi: 10.1016/j.fertnstert.2013.11.008

75. Menezo YJ, Silvestris E, Dale B, Elder K. Oxidative stress and alterations in DNA methylation: two sides of the same coin in reproduction. Reproductive Biomed Online. (2016) 33:668-83. doi: 10.1016/j.rbmo.2016. 09.006

76. Silvestris E, Cohen M, Cornet D, Jacquesson-Fournols L, Clement P, Chouteau J, et al. Supporting the one-carbon cycle restores ovarian reserve in subfertile women: absence of correlation with urinary bisphenol A concentration. BioRes Open Access. (2017) 6:104-9. doi: 10.1089/biores.2017.0016

77. Dattilo M, Cornet D, Amar E, Cohen M, Menezo Y. The importance of the one carbon cycle nutritional support in human male fertility: a preliminary clinical report. Reproduc Biol Endocrinol. (2014) 12:71. doi: 10.1186/1477-782712-71

Conflict of Interest Statement: The authors declare that the research was conducted in the absence of any commercial or financial relationships that could be construed as a potential conflict of interest.

Copyright (c) 2019 Silvestris, Lovero and Palmirotta. This is an open-access article distributed under the terms of the Creative Commons Attribution License (CC BY).

The use, distribution or reproduction in other forums is permitted, provided the original author(s) and the copyright owner(s) are credited and that the original publication in this journal is cited, in accordance with accepted academic practice. No use, distribution or reproduction is permitted which does not comply with these terms. 